\title{
Level II Milestone Review of LLNL Program on Grain- Scale Dynamics in Explosives
}

Malcolm F. Nicol, UNLV, David J. Benson, UCSD, and Stanley Yip, MIT

U.S. Department of Energy

\section{January 14, 2003}

Lawrence

Livermore

National

Laboratory 


\section{DISCLAIMER}

This document was prepared as an account of work sponsored by an agency of the United States Government. Neither the United States Government nor the University of California nor any of their employees, makes any warranty, express or implied, or assumes any legal liability or responsibility for the accuracy, completeness, or usefulness of any information, apparatus, product, or process disclosed, or represents that its use would not infringe privately owned rights. Reference herein to any specific commercial product, process, or service by trade name, trademark, manufacturer, or otherwise, does not necessarily constitute or imply its endorsement, recommendation, or favoring by the United States Government or the University of California. The views and opinions of authors expressed herein do not necessarily state or reflect those of the United States Government or the University of California, and shall not be used for advertising or product endorsement purposes.

This work was performed under the auspices of the U. S. Department of Energy by the University of California, Lawrence Livermore National Laboratory under Contract No. W-7405-Eng-48.

This report has been reproduced directly from the best available copy.

Available to DOE and DOE contractors from the

Office of Scientific and Technical Information

P.O. Box 62, Oak Ridge, TN 37831

Prices available from (423) 576-8401

http: / / apollo.osti.gov/bridge/

Available to the public from the National Technical Information Service

U.S. Department of Commerce 5285 Port Royal Rd., Springfield, VA 22161 http:/ / www.ntis.gov/

OR

Lawrence Livermore National Laboratory Technical Information Department's Digital Library http:/ / www.llnl.gov/tid/Library.html 


\section{Level II Milestone Review of LLNL Program on Grain-Scale Dynamics in Explosives}

This document describes an evaluation of the Level II Milestone achievements of the LLNL program on Grain-Scale Dynamics in Explosives on January 14, 2003. The evaluation team included Prof. Malcolm Nicol, Chair, (UNLV), Prof. David Benson (UCSD), and Prof. Sidney Yip (MIT). The Grain-Scale Dynamics in Explosives Program, led by Jack Reaugh, is a mixture of advanced computational methodology and physico-chemical theory applied to understanding deflagration and detonation of plasticbonded explosives from the nano to the macro scales. At many points, the modeling is tied directly to experiments within the precisions of both.

Advances are needed in the experimental, theoretical, and computational aspects of detonations. Work reported in this review represents significant, cross-pollinating advances in each area. The team successfully carried out ALE-3D simulations of deflagration in PBX with grain scale effects. (Milestone requirements 1 and 2), interpreted experimental data on flame speed vs. pressure and sensitivity to global kinetics in terms of ALE-3D simulations (Milestone requirement 3), and used the results of these simulations to develop a continuum reactive flow model that captures some of these effects (Milestone requirement 4). By comparing experiments and detonation velocities in small diameter, unconfined explosives, they found non-idealities that remain at intermediate diameters (ca. $1.5 \mathrm{~mm}$ ) that require further analysis. In all of these areas, the project team has met, indeed exceeded, their Level II Milestone goals.

We are particularly impressed by the ALE-3D development for reactive flow by Albert Nichols that includes substantial advances in the-state-of-the-art that deserve individual recognition. He should be encouraged to publish his work in journals. In particular:

1. The new thermal coupling algorithm is self-consistent, more accurate than the usual $1^{\text {st }}$ order scheme, and increases the overall robustness of the calculation by eliminating nonphysical excursions in the solution variables.

2. There has been important progress associated with the transport of discontinuous solution variables. The developments here should also be applicable to other problems with discontinuous variables, for example, material damage, where "healing by advection" has been a long-standing problem in Eulerian and ALE hydrocodes.

3. Linking the finite element code TOPAZ to ALE-3D is an important accomplishment. While ALE-3D has the temperature at the element centroid, TOPAZ has its temperatures centered at the nodes. The difficulties associated with linking the two codes were identified and solved with a physically based subgrid conduction model. This approach may be extensible to other situations involving multi-physics, multi-code problems. For example, Godunov codes have all the solution variables, 
including the velocity, at the zone centroid. This makes linking them to finite element and finite difference codes using staggered meshes difficult.

4. The numerical modeling of the HE burn process, which combines CFD level set methods with the explicit ALE hydrodynamics and explicit finite element thermal transport, is an important contribution in its own right. Competing efforts at other DOE laboratories have involved more people and met with less success.

The overall report (UCRL-ID-150388, "Grain-Scale Dynamics in Explosives," John E. Reaugh, September 30, 2002) and presentations (UCRL-PRES-150298 Rev. 1) are exceptionally well delivered with logical layouts that carefully point out achievements, limitations of the work to date, and directions for future efforts. This is frontier work of an excellent level that should be published in a high-profile journal. We compliment LLNL for having assembled this high-quality team.

Recommended Future Collaborations and Directions

\section{Structure of PBX, creating a grain model}

The present method used seems to be sound. However, we question whether the grain distributions are too complex? That is, might simple distributions with $0.3 \times 0.3$ $\mathrm{mm}$ or smaller samples be equally effective for testing and improving the model?

It also would be useful to characterize the resulting grain distributions for each model generated, such as radial distribution function (overall and differentiated with regard to species or grain orientations) and orientation distributions. What would an amorphous sample of the same mixture look like in these various measures? It would be good to keep in mind that some of the details built into the model may get washed out later when it comes to their effects on deflagration. What might be the effects of different realizations of the defects, e.g., cracks?

\section{Uncertainties and Reproducibility}

What are the uncertainties and reproducibilities of the results? For example, how similar are the rate equations for the $90.1 \times 0.1 \mathrm{~mm}$ subblocks of the $0.3 \times 0.3 \mathrm{~mm}$ calculation or the isolated $0.1 \times 0.1 \mathrm{~mm}$ block?

\section{Transport properties}

It is useful to develop an effective Enskog theory since this is computationally most efficient. However, one does not have to rely on such approximations if there is only a small number of species, concentrations, ... most critical variables to examine. For these, one can do a full MD simulation and obtain the transport coefficients through GreenKubo formulas. Since transport on short time scales is of interest, it may be necessary to consider some frequency dependence. 
4. Discussion of resolution of difference between experimental and calculated flame speed (Fig. 17) on p. 35 of Reaugh Report

The new understanding is that $\mathrm{D}$ and $\mathrm{K}$ behave differently at high pressure (Fig. 19). This point should be pursued further by studying carefully both quantities using full MD machinery. One purpose would be to explain the physical mechanisms underlying the behavior of $\mathrm{K}$ (and also $\mathrm{D}$ which appears to be simpler) seen in Fig. 19, drawing some general conclusions about the danger of applying low-pressure fits at high pressures. Another purpose could be to show the difference, if any, between transport in a uniform medium as opposed to a heterogeneous environment. Are the grain-scale effects evident in the transport properties?

\section{An improved strength model for HMX}

HMX is a strongly anisotropic brittle crystalline material. The current isotropic Steinberg-Guinan model for HMX, which is also used in other outside research efforts, leaves a lot to be desired. Void collapse calculations in metal single crystals have shown that the behavior is significantly different than for isotropic materials. Since void collapse is the primary mechanism for hot spot formation in PBXs, an accurate model of the HMX is critical to the overall accuracy of the simulations. The logical starting point for an improved strength model is single crystal plasticity. Fortunately, Dr. Richard Becker, currently in the ALE3D group, is an expert in single crystal plasticity, and he is currently having a single crystal plasticity model which also includes phase changes implemented into ALE3D. The energetic modeling effort should take advantage of this research in their backyard. 